\title{
Vocabulário, consciência fonológica e nomeação rápida: contribuições para a ortografia e elaboração escrita
}

\author{
Maria Thereza Mazorra dos Santos ${ }^{1}$
}

Santos MTM. Vocabulário, consciência fonológica e nomeação rápida: contribuições para a ortografia e elaboração escrita [tese]. São Paulo: Faculdade de Filosofia, Letras e Ciências Humanas da Universidade de São Paulo; 2007. 295 f.

O objetivo dessa pesquisa foi compreender os processos lingüísticos que subjazem à aprendizagem da linguagem escrita, o desenvolvimento de um protocolo de análise de redação, assim como a correlação entre esses processos lingüísticos e a produção escrita. Participaram deste estudo 82 alunos de $3^{\mathrm{a}}$ série do Ensino Fundamental de escolas particulares e municipal, com idades entre nove e dez anos, residentes em municípios da região oeste da Grande São Paulo. Esta pesquisa foi divida em três estudos. No Estudo I foram analisados os desempenhos dos sujeitos em provas de vocabulário, consciência fonológica e nomeação rápida de objetos, cujos resultados se mostraram adequados para a faixa etária estudada. No Estudo II analisamos a produção escrita em ditado de palavras e pseudopalavras e elaboração de uma narrativa escrita. Concluímos que os erros fazem parte do processo de desenvolvimento da escrita, mas é necessário também que se compreenda que estratégias a criança utiliza para escrever. Em relação à redação concluímos que, apesar de ainda não dominarem todo o esquema narrativo, as crianças apresentaram um conhecimento lingüístico que lhes permitiu escrever histórias originais em forma de narrativa. $\mathrm{O}$ protocolo proposto se mostrou uma ferramenta prática, que possibilitou uma avaliação minuciosa dos diversos aspectos envolvidos na elaboração da redação. O Estudo III indicou correlações entre o desempenho nas provas de vocabulário, consciência fonológica e nomeação seriada rápida e o desempenho ortográfico, assim como com a produção de uma narrativa escrita.

Trabalho realizado no Laboratório de Investigação Fonoaudiológica em Desenvolvimento da Linguagem e suas Alterações do Departamento de Fisioterapia, Fonoaudiologia e Terapia Ocupacional da Universidade de São Paulo - USP - São Paulo (SP), Brasil, sob orientação da Profa. Dra. Debora Maria Befi-Lopes.

(1) Doutora em Semiótica e Lingüística Geral pela Faculdade de Filosofia, Letras e Ciências Humanas da Universidade de São Paulo - USP - São Paulo (SP), Brasil; Colaboradora do Laboratório de Investigação Fonoaudiológica em Desenvolvimento da Linguagem e suas Alterações do Departamento de Fisioterapia, Fonoaudiologia e Terapia Ocupacional da Universidade de São Paulo - USP - São Paulo (SP), Brasil.

Endereço para correspondência: Maria Thereza Mazorra dos Santos. Al. Rio Negro, 911, Conj. 707, Alphaville, Barueri - SP, CEP 06454-060. Email: tetemazorra@thot.com.br 